\title{
Reflections on Public Participation in Urban Planning Hui $\mathrm{Ma}^{1, \mathrm{a}}$ \\ ${ }^{1}$ Beijing Weibang Yatai Planning Co., Ltd. Dongcheng Dist, Beijing, 100007 aemail,
}

\author{
Keywords: Urban Planning; Public Participation; Problem Analysis
}

\begin{abstract}
Under the premise of very limited urban resources, urban planning mistakes can lead to huge waste and in the process of urban planning, stakeholders are active and extensive participation is an important factor to ensure the objective and scientific nature of urban planning. Therefore, public participation in urban planning is not only an important manifestation of the government's right to public democracy and it is an important measure to enhance the harmonious relationship between the government, the planning department and the people. It is also an important measure to ensure the tripartite sharing of planning achievements. However, it is of great practical significance to discuss the problems of public participation in urban planning because of the unsatisfactory public opinion, enthusiasm and participation effect of public participation in urban planning. This paper analyzes the positive and negative significance of public participation in urban planning, analyzes the existing problems of public participation in urban planning and puts forward specific suggestions.
\end{abstract}

\section{Introduction}

Based on the perspective of urban management, urban planning is the comprehensive development of urban construction to the specific period of construction and planning, so as to improve the rationality and intensification of urban resource application and maximize the role of urban resources. To a certain extent, urban planning is an important basis for urban construction and management. Public participation is a formal institutional arrangement that occupies an important place in urban planning work programs. However, in the actual planning operation, the public participation system is usually simplified and marginalized and the public does not really participate in the planning decision-making, so this study is aimed at the problems of public participation in urban planning in China, and puts forward the solution.

\section{The Significance of Public Participation in Urban Planning}

To a certain extent, the significance of public participation in urban planning shows a positive side, but there are some negative implications. The positive significance of public participation in urban planning is manifested in two aspects: on the one hand, social pluralistic democratic governance is an important category in public governance theory, which requires the active participation of the public in social governance, and public in urban planning Participation is an important manifestation of the idea of pluralistic democratic governance. At present, some local government cities in China also have a certain utilitarian blind can not accurately grasp the pattern and direction of urban construction. Public participation in urban planning can improve the coordination of some of its work, the formation of guiding effect for urban planning to create better conditions. On the other hand, public participation in urban planning can achieve the benign exchange between the government and the people, effectively solve the problem of information island avoid duplication give full play to the role of urban resource sharing.

Although public participation in urban planning has significant positive significance, but there are also some negative significance, the same performance in the following two aspects: on the one hand, the public community, its individual comprehensive quality, educational background, living environment , Professional ability and so there are many differences, resulting in each individual for the urban planning of the different points of view, the public is likely to be driven by different 
interests of thinking, behavior conflict, thus affecting the city's planning and construction. On the other hand, the public often participates in urban planning in the form of representative groups. Each member of social organization has the same interests and demands the same, and enhances the public's ability to express his own demands. But this public representative group is still able to represent a very small number of people, which in essence still belong to the scope of personal interests, which may eventually conflict with the real public interest, and may evolve into intense public opinion, leading to the city Planning and construction have been negatively affected.

\section{The Problem in the Urban Planning Public Participation}

Specifically, at present, the problems of public participation in urban planning in China are mainly reflected in the following aspects:

Public Awareness of Urban Planning Is Weak. First of all, although the public is the main body of urban planning, but the above also mentioned members of the public group of knowledge, professional competence, living environment, there is a big difference, a large part of the public lack of understanding of planning expertise, even if the government the relevant planning drawings and content cannot be explained in depth, so the willingness to participate in urban planning is not strong, the lack of active participation in some planning projects enthusiasm. Second, Chinese public awareness of the importance of participation in urban planning for a long time, that urban planning is the work of government departments, and their own no direct relationship, only their own interests will be violated when the rights awareness; and Chinese urban planning to the government mainly, the public on their own right to exercise the lack of knowledge, not in-depth participation in urban planning. Finally, urban planning involves a wide range, most of which are not directly related to the vital interests of the public, so the public's attention to urban planning is not high; even if some of the planning involves the direct interests of the public, but because of the feedback mechanism is not perfect, the public do not know whether their views are adopted, whether the urban planning had a direct impact, so participation is not high, participation is not strong.

The Participation Mechanism Needs to be Improved. At present, China has entered the socialist transition period, but the thinking inertia of the planned economy era will still have an impact on the people, urban planners and decision makers, whether it is the organizational stage of urban planning or decision-making stage, did not achieve "government- Market with "the basic requirements. On the one hand, the government has a completely monopolistic planning organization, the management power is highly centralized, and the government has often carried out its "planning right" and "examination and approval right" in the urban renewal. The government adopts the "one size fits all" means. On the other hand, the government in order to attract investment in the urban planning arrangements may be for developers to provide various preferential conditions, the most direct and most important indigenous people are completely placed in the project decision-making and operational procedures, leading to the public city planning authority, seriousness and even legitimacy have questioned.

Public Participation Is Not Enough in Depth and Breadth. At present, most of Chinese urban planning mainly through the organization of hearings, experts visit issue a questionnaire survey, etc. to guide public participation, in order to achieve public participation in the breadth and depth of the purpose. But in the actual urban planning effect is far from satisfactory. Mainly due to the low level of public participation Although the public participation in urban planning has risen to the legal level, but the relevant legal provisions only for public participation in urban planning rights, obligations of a generation, the lack of a sound regulatory system cannot effectively implement the public participation system, so the public planning of China participation is still in the "symbolic participation" stage, the public has no decision-making power. On the other hand, in the urban planning, although the general public in the number of absolute superiority, but its strength scattered, in the actual participation of the lack of organizational support, individual strength is difficult to achieve collective action cannot achieve the depth of breadth of public participation in the government Leading the process of planning, the public can not form a considerable balance with 
other representatives of the trend.

\section{The Effect Strategy to Improve Public Participation in Urban Planning}

In view of the existing problems of urban planning public participation at present, it is suggested to improve from the following aspects:

Improve the Overall Quality of the Public to Create A Good Public Participation Atmosphere. The government should increase publicity for urban planning, raise public awareness of urban planning, and learn more about the relevant knowledge. You can learn from foreign experience, led by the government from the school began to plan knowledge popularization, lectures, or in various industries, various units held seminars, guide different occupations, different cultures more people involved in urban planning, with the government face to face communication, express their own demands, will. The government can hire professional planners, college planning professional instructors to carry out various types of urban planning knowledge lectures, into the urban communities, schools, institutions, units to carry out publicity seminars to encourage more public participation in the primary and secondary schools that can train students Participation in awareness, with easy to understand the language so that primary and secondary students understand the meaning of urban planning, content, its rights and obligations, to enhance its sense of pride and belonging to the city, for its follow-up to urban planning to lay the foundation.

Enrich the Public Participation Channels. Government departments can guide the public through different forms of participation in urban planning, through a variety of ways to expand the channels of public opinion collection, and constantly improve the public opinion expression rules and information guidelines to ensure smooth and convenient public participation channels to improve the scientific and rational decision-making of urban planning. Specific public participation in the form of public forums, seminars, or in the project building community to set up advisory groups, advisory committees, to facilitate public comments and questions. But also can give full play to the important role of information means, the use of network technology to the community to solicit opinions and suggestions, widely consult the views and suggestions of various stakeholders, and within a certain range of open debate, dialogue and exchange. In addition, a sound government feedback response mechanism should be established to promptly publish the results of public opinion and to ensure that the feedback object can obtain timely feedback.

Improve the Urban Planning Public Participation Mechanism. Generally, the public participation mechanism of urban planning includes three aspects: planning permission, planning enforcement and planning evaluation, and further improve the public participation mechanism according to the characteristics of different processes. First of all, in the planning permission stage, before the project approval by the development of the main body to submit a "two books" application, and apply for planning permission before the relevant interest groups to issue a circular and consultation, the implementation of four neighbors system. The planning department shall, after receiving the application for permission to submit the development subject, examine the application materials and formally accept the application for planning permission. During the public announcement period, the public comments and suggestions on the application plan. The planning department collects and collates public opinions, makes preliminary planning permission decision, and gives feedback to the public. If the project is significant, it is necessary to conduct a planning permit hearing, invite the parties to conduct a hearing, organized by the planning department and host. After the approval of the planning permission must be announced planning permission results, such as the public has a new opinion to submit and submit new evidence, the planning permission to be reasonable, the feasibility of re-assessment, and ultimately make a decision. Second, the planning and enforcement stage of its main procedures includes project start participation, construction process participation, project completion and so on. After the approval of the development of the main planning permission to the community, especially the neighboring areas of the residents inform the project in detail. During the construction process, the public should assist the planning department in supervising the development subject, and the planning department should consult the public's supervision opinions extensively and make the decision. After the 
completion of the project development of the main body must submit to the planning department to complete the project acceptance of the application, the competent departments to do on-site investigation, consult the public comments, and then according to the results of the survey, public opinion and so make the final decision and feedback to the public information. The planning and evaluation is the last step of the city planning. The planning department should examine the correspondence between the planning and implementation plan, and evaluate the effect and impact of the project after the implementation of the project, so as to provide the guiding suggestions for the follow-up urban planning and development.

\section{References}

[1] Lin Hongchao, Li Yanjie. Public participation in the administrative planning process: the ideal and misunderstanding - from the Wenchuan earthquake recovery and reconstruction planning [J]. Politics and Law. 2016 (05)

[2] Chen Zhenyu. Uncertain legal concept and judicial review[J]. Journal of Yunnan University (Law Edition) .2016 (04)

[3] Lan Yan Zhuo. Decision-making and public opinion: public participation in urban planning changes [J], economic and social system comparison, 2014 (15)

[4] Sun Shiwen, Yin Yue. Theoretical Basis and Development of Public Participation in Western Urban Planning[J]. Foreign Urban Planning, 2014 (19)

[5] Zou Bing, Fan Jun, Zhang Yongbin, etc. From consulting the public to the common decision-making - the practice and enlightenment of the whole process of Shenzhen city master planning[J]. Urban Planning, 2016 (8)

[6] Wei Biao, Dai Zhemin.Study on Public Participation in Urban Planning Activities in China and Britain in Comparative Perspective - Based on the Analysis and Implications of Hangzhou and London Time [J]. Urban Planning, 2015 (5) 